\title{
Townhouse residents' use of interior products in the social zones of their homes as a demonstration of their need for uniqueness
}

Alet C Erasmus, Lorna Christie \& Judy Kleyn

\author{
Corresponding author: Alet C Erasmus \\ Department Consumer Science \\ University of Pretoria \\ Private bag X20 \\ Hatfield \\ 0028 \\ Phone number: 0827842467 \\ Fax number: 0124202855 \\ e-mail address: alet.erasmus@up.ac.za \\ Lorna Christie \\ Research performed as part of Masters degree \\ Department Consumer Science \\ University of Pretoria \\ Judy Kleyn \\ Department of Statistics \\ University of
}

\begin{abstract}
Town houses or cluster homes refer to housing developments where the exterior façade of adjacent units are architecturally identical or very similar. A pertinent disadvantage of this type of tenure is that residents are not allowed to alter the exterior of their homes to reflect personal differences. This study focussed on the probability that residents in these type of townhouses would make intentional effort to demonstrate their uniqueness through counter-conforming choice of interior objects for the social areas of their homes where guests are received and entertained. The study involved 182 respondents who lived in townhouses in a major urban area in South Africa who were recruited through convenient snowball sampling. Findings indicate that townhouse residents' interior product decisions are predominantly of a creative counter conformity nature which is the safer alternative than avoidance of similarity or unpopular choice counter-conformity practices that might evoke criticism from peers or reference groups. Interior product choices are therefore predominantly cautious and aimed to evoke the admiration of others rather than critique. A positive outcome of this study in terms of future research is confirmation of the usefulness of the measuring instrument, which was originally developed for clothing research. Findings are insightful for property developers, interior designers, interior decorators and retailers in terms of consumer facilitation and the appropriate marketing of interior products.
\end{abstract}


Key words: Need for Uniqueness, Counter-conformity, Extended self, cluster homes, Interior decisions, Housing

\section{INTRODUCTION AND PROBLEM STATEMENT}

A family's housing purchase decision is one of the most important, involving and risky decisions that they would have to deal with as an entity over time. All cultures and socio-economic groups can identify with the stress associated with the intricate home purchasing process (Han, 2013; Lee and Reed, 2014; Rahman and Harding, 2014; Zhang et al., 2014). Some of the desirable characteristics of a home are relatively easy to determine, assess and express when trying to match prospective buyers with their ideal or dream home (Maury and Tripier, 2014) for example attendig to functional performance utility such as the size and structure of the shelter (Casimir and Tobi, 2011; Flambard, 2013; Han, 2013; Lee and Reed, 2014). However, one's home in terms of its size, architectural features, structure, condition and location are also used to deduce and signify the family's socio-economic status that have considerable long-term repercussions (Schiffman and Kanuk, 2010, p. 344), as well as the residents' lifestyle and taste which differs considerably across different cultures and which may change notably over time (Guest editorial, 2009). Other features, however, are less tangible, more intricate, extremely difficult to verbalise (Zhang, et al., 2014) and are often neglected during the purchase process (Fischer and Stamos, 2013) which may eventually leave no other option other than to make costly amends through renovations. Housing also influences residents' identity construction (Kemeny, 1992; Miller, 2001; Clapham, 2005), esteem- and self-actualization levels which go beyond features associated with the basic structure of the dwelling and social implications (Lamb et al., 2004, p. 84). Quitzau and Røpke (2008) for example highlight home owners' increased demand for image-based home renovations since the 1930's as an expression of a need for individual and family identity, which is further fuelled by fashion trends. Apparently kitchens and bathrooms that contain multiple fixtures are often refurbished to reflect residents' uniqueness. Housing choices and home alterations may however eventually be determined by the level of control that prospective home buyers have, as explained by capital theory (Adriaenssens and Hendrick, 2009), i.e. the unfortunate reality that affordability may exceed other needs and preferences of the family (Lee and Reed, 2014). Home owners who idealise a unique home which expresses their personal characteristics and which differs from surrounding houses, may experience housing stress when they fail to achieve their ideals (Rahman and Harding, 2014).

Housing alternatives in a country portray much of the economic, social and political conditions in a country or an area at a given point in time (Rahman and Harding, 2014; Bowers and Manzi, 2006; Jürgens and Gnad, 2002). A specific form of housing that has adorned the streets of many cities in Europe for centuries, and which has gained popularity in countries such as South Africa near the turn of the century, is cluster homes which include townhouse complexes. Many of these developments are in enclosed security complexes, where housing units may be free standing or attached with a secure entrance which limits access to the complex (Roth, 2006, p. 20). Despite numerous advantages 
associated with townhouse living such as security, status, lifestyle, financial and mobility factors (Coy and Pöhler, 2001; Delport, 2002, p. 9; Hook and Vrdoljak, 2002; Jürgens and Gnad, 2002; Sanchez et al., 2005; Blandy, 2006; Morgan, 2009), cluster homes unfortunately have pertinent drawbacks that are often overseen by estate agents during their interaction with prospective home buyers. The implementation of universal design, which refers to design that meets the requirements of people of all ages and abilities (Nunn, 2009) may be too restrictive in terms of satisfying individual needs even though it proposes a very logical approach in cluster housing developments where the same construction needs to be appropriated for diverse home buyers. This study concerns itself with the fact that it is not clear how disadvantages of this nature influence prospective home buyers and how they eventually compensate for it when they cannot afford to avoid it.

This study focuses on a specific disadvantage of cluster homes which is not unique to the South African context (Quitzau and Røpke, 2008), namely that the exterior façade as well as certain fixtures of the interior of individual homes in particular developments are identical or very similar. Generally, the elected committee that administers matters of mutual concern in a specific housing development forbids changes to the exterior of individual units to maintain and protect a coherent theme across the development, even with regard to the maintenance of gardens and mutual amenities (Jürgens and Gnad, 2002). Any form of housing where residents are not allowed to alter the exterior of their homes, prevents homeowners from personifying their homes and from utilising their home to express their extended selves to onlookers - a phenomenon that dates back centuries. For example, in the early 18th century, when Dublin became one of the British Empire's most flourishing cities, impressive Georgian homes were built outside the walls of the original medieval town. As with cluster homes and townhouse complexes today, the exteriors of these homes were uniformly built, often identical. Strict rules based on rigid architectural guidelines were enforced by the developers, which home owners had to follow in the finest detail. The story of the famous colourful doors of Dublin in Ireland goes that late one night, a resident who had drunk too much Guinness got lost on his way home because all the terrace houses looked the same. He then stumbled into the wrong house and into the wrong bed. The next morning, all the women painted their doors differently in vibrant colours and to this day, the "famous doors of Dublin" are a colourful reminder of residents' efforts to set themselves apart from their neighbours (The Past Whispers).

As is the case with one's clothing, the house a person lives in also serves as an extension of one's self (Fernandez, 2008) and may be used intentionally to communicate characteristics of the owner, and even to indicate residents' social position in society (Tian and Belk, 2005; Lollar, 2010). Many scales that have been used to measure socioeconomic status include housing as a criterion (Schiffman and Kanuk, 2010, p. 344) or even rely on housing (Dunn, 2002). One's home furthermore also serves as an avenue to portray residents' extended selves (Gunter, 2000, p. 4-16; Moore, 2000) and to accomplish this, home owners use various props to alter the exterior of their homes in much the same way as was done in Ireland in the nineteenth century, as well as in the interior of their homes. Mostly, the 
interior of a cluster home may eventually provide the only avenue to express the self of the owners. Through intentional choice and display of interior objects in the social zones of their homes where outsiders are admitted and entertained, residents then attempt to project their extended selves and differentiate themselves from others.

In order for a home to be associated with a person, the interior should be representative of the home-owner's extended self/ identity and this can be achieved through the choice and acquisition of interior objects and the overt display of selected items in one's home (Kilmer and Kilmer, 1992, p. 520; Creusen and Schoormans, 2005). Subsequently, interior design (Kilmer and Kilmer, 1992, p. 2) and interior decorating (Pitrowski, 2004, p. 3-4; Binggeli, 2007, p. 7-10) are key components in the transformation of a house into something that signifies a resident's extended self. A person's identity formation and display of identity through the interior of one's home relies on the individual's interaction with other people and the ability to interpret specific messages (Schultz et al., 1989; Solomon, 2007, p. 72). According to Blumer's explanation of symbolic interactionism (in Kaiser, 1998, p. 23, 322-323) people share meanings through a process of interaction, i.e. people use symbols and objects as tools to communicate to others in a social context and to maintain social meanings within their environment. In order to express one's extended self an individual will therefore make use of social objects to portray an identity that is revealed to onlookers (Charon, 1979, p. 22; Kaiser, 1998, p. 23; Sandstrom et al., 2006, p. 1; Nussbaumer, 2009, p. 28-29).

Literature suggests that all people, to some degree, have a need to be unique (Tian and McKenzie, 2001). When people's identities are threatened because they are typecast and perceived to be highly similar to others, they tend to behave in a counter-conforming manner to reduce the threat (Tian et al., 2001). This need to counter-conform is none other than a need for uniqueness, which comprises three possible avenues, namely creative choice counterconformity (CCC), unpopular choice counter-conformity (UCCC) and avoidance of similarity (AOS) (Tian et al., 2001). Creative choice counter-conformity represents choices that are unusual but still accepted by one's reference group, even though these choices are novel compared to average product choices. Unpopular choice counter-conformity represents product choices that deviate slightly from the social norms of a person's reference group and which may provoke social scrutiny and criticism. However, the reference group in the long run accepts such products, and the person will be seen as a trendsetter. Avoidance of similarity represents a choice of products that is acceptable by a person's reference group, although the products are rarely chosen by others and are the exception rather than the rule. Typically the users discontinue using such products when they become popular and then acquire replacements so that their use of products remain unusual (Tian and McKenzie, 2001; Tian et al., 2001; Ruvio et al., 2008). Literature therefore suggests that consumers will try to distinguish themselves from others in a more, or less explicit way in terms of their product choices. The well-known Dublin doors is probably one of the best examples of consumers' need for uniqueness and counter conformity behaviour in a housing context. 
In order to confirm different levels of uniqueness, a 'Need for Uniqueness Scale' was developed by Snyder and Fromkin in 1977 within a behavioural frame of reference (Tepper and Hoyle, 1996). This scale has since been implemented in multiple contexts relating to clothing, activities and hobbies (Tepper and Hoyle, 1996; Simonson and Nowlis, 2000; Workman and Kidd, 2000; Tian and McKenzie, 2001; Tian et al., 2001; Ruvio et al., 2008). Evidence could however not be found that the scale has been used in the context of housing or interior before. Inspired by literature that suggests that clothing does for the human body what a home's interior does for the home (Belk, 1988), as well as evidence that one of the important functions of clothing is to serve as an extension of the self (Workman and Kidd, 2000), the scale used by Tian et al. (2001) in a clothing context was slightly adapted for this study to deduce home owners' need for uniqueness from their interior product choices. This study therefore proposes that one's home could serve, and intentionally be used as an extension of the self. Tepper and Hoyle (1996) state that consumers' expression of uniqueness can manifest in the form of personal or material possessions, indicating that the need for uniqueness scale could be useful to examine underlying reasons for consumers' choice of interior objects in their homes. A person's need for uniqueness is a pursuit to distinguish oneself from others within a particular social group, whilst indicating which social group he/she belongs to. People's consumption of objects will, through the communication process, transfer personal and social messages to others provided that onlookers understand and share the underlying meanings of objects in their social surroundings (Schiffman and Kanuk, 2010, p. 372-373).

\section{RESEARCH AIM}

Generally, guests are received and entertained in the social zones of people's homes and therefore residents would more explicitly try to create a favourable impression in those areas. With reference to residence in town houses, which represent a specific form of cluster housing, this investigation aimed to provide empirical evidence of residents' need for uniqueness through their choice of interior objects, particularly for the social zones of their homes. The study investigated residents' counter-conformity behaviour in terms of their choice of interior products, i.e. attempts to use interior products to distinguish their homes and themselves from others within the same residential complexes where the exterior façade as well as the interior fixtures of adjacent units are visually identical or highly similar. The study furthermore investigated the level of effort that residents would make to overtly express their need for uniqueness to peers and reference groups (if any), namely creative choice counter-conformity; unpopular choice counter-conformity or avoidance of similarity. These are efforts used to increase one's housing satisfaction and to enhance a sense of place attachment. 


\section{CONCEPTUAL BACKGROUND}

\section{The home and its interior}

Dwellings are concurrently optimised as objects and spaces of consumption where the various elements of the home, including the physical structure, related services, performances, information and ambience are consumed and appreciated within residents' discretion (Warde, 2005, p. 137). The home serves as an indication of the residents' social position (Adams, 1984; Guest editorial, 2009; Schiffman and Kanuk, 2010, p. 344) and is therefore an appropriate avenue to portray their extended selves. Interior design, which involves the manipulation of interior objects in a functional, and ergonomic manner which are conducive to the lifestyle of the residents (Kilmer and Kilmer, 1992, p. 2) as well as interior decorating, which refers to the aesthetic adornment of the home (Pitrowski, 2004, p. 34; Binggeli, 2007, p. 7-10) are therefore fundamental to transform a house into a home. In order for a home to be associated with a specific person, the interior should reflect the home-owner's extended self (Kilmer and Kilmer, 1992, p. 520; Creusen and Schoormans, 2005) and this can be accomplished through display of interior objects in one's home with the assistance of specialists such as interior designers or interior decorators but might also be attempted by the home owner self.

\section{Manifestation of an extended self through the interior of a home}

Identity is an on-going process. It is shaped through a self-categorization process that is formulated within a social context within a person's social group (Stets and Burke, 2000; Kempen and Ozaki, 2006). One's home has private and social zones. Traditionally, interaction with guests takes place in the social zones of one's home which provide the ideal opportunity for residents to adorn these areas in a manner that reveals, through conspicuous consumption, what a person wishes to communicate to others about the self (Kilmer and Kilmer, 1992, p. 205; Allen et al., 2004, p. 205; Nielson and Taylor, 2007, p. 129). Consumption is an integral part of the communication process, whereby objects such as one's possessions that are used in social context, transfer personal and social messages to others (Van Gorp, 2005) and people may even intentionally use products to convey specific information to others. It is hence imperative that people understand the underlying meanings of objects, and that they have the ability to choose objects that are acceptable in their social surroundings.

\section{Expression of place identity}

Inevitably all aspects of a person's extended self will in some way have place related implications. Individuals develop a bond that is attached to a certain place through emotional content, and will therefore construct place identities that bind them symbolically and emotionally to a specific place (Knez, 2005). Place identity is connected to an individual's sense of self and represents a cognitive structure that contributes to an individual's self-categorization and social processes (Kempen and Ozaki, 2006; Mannarini et al., 2006). Identity is the personification of qualities that are 
expressed in tangible ways to distinguish one person from others (Rengel, 2007, p. 257). Place identity as part of the extended self is therefore not restricted to a distinction between a person's self and significant others, but also includes the objects and places in which they are found (Knez, 2005; Kempen and Ozaki, 2006; Kopec, 2006, p. 62). According to Belk (2010), one's home therefore serves as the locus of the extended self.

A distinction should however be made between a sense of place, place attachment, place dependence and a place identity. A sense of place is merely an experimental process that is created by a setting, in combination with what a person brings to such a place. A sense of place creates a feeling of belonging. Place attachment refers to people's bonding with various places through identity-related aspects as well as objective criteria (Moore, 2000; Kempen and Ozaki, 2006; Kopec, 2006, p. 62; Nussbaumer, 2009, p. 31) while place dependence is the perceived strength between the association of a person and a specific place. Place identity, on the other hand, is the development of the dimensions of the self, in relation to the physical environment (Manzo, 2003; Nussbaumer, 2009, p. 31). Place identity can thus be classified as the interpretation of the self that provokes a sense of being at home. Furthermore it is the interpretation of the self, which is represented through environmental meaning to symbolize identity (Cuba and Hummon, 1993). Place attachment and place identity are closely related, since both are concerned with the bonds between people and places. Place identity is derived from an initial attachment to a certain place. This attachment however evolves and adjusts to enable a continuity of one's identity as one's environments change over time (Mannarini et al., 2006; Moore, 2000).

This study therefore proposes that, in order to establish an own identity, and to secure place identity when residing in a cluster home where neighbouring homes are identical or highly similar:

$\mathrm{H} 1$ : Residents of cluster homes will optimise the interior to distinguish their homes from others by demonstrating counter conformity behaviour when choosing interior products for their homes.

Due to stronger involvement with interior purchases:

H2: Females' choice of interior products for their homes will demonstrate stronger counter conformity behaviour compared to males.

Because a need for uniqueness is a personal trait rather than a characteristic determined by socio-demographic characteristics:

H3: Counter conformity behaviour is not restricted to households with higher incomes.

H4: Counter conformity behaviour is not restricted by income level.

H5: Residents who own the property will demonstrate significantly stronger counter-conformity behaviour. 
H6: Residents who have resided in the cluster homes for a longer period will demonstrate significantly stronger counter-conformity behaviour.

\section{RESEARCH DESIGN AND METHODOLOGY}

The research was cross sectional, exploratory and descriptive in kind. The deductive approach involved an extensive investigation of existing literature relating to housing; interior design; identity formation; need for uniqueness; place attachment - all framed within the assumptions of the symbolic interactionist perspective. The survey involved a structured questionnaire of which four sections, namely the demographic information; the section dealing with residents' need for uniqueness; criteria used to select interior purchases for the social zones of their homes; and enquiry about the sources of inspiration for their interior decisions are relevant to this publication. Questionnaires were pre-tested with individuals who met the criteria for participation to clarify ease of completion in terms of the wording as well as the interpretation of the scales, and to determine the time required for completion.

The established Need for Uniqueness scale of Tian et al. (2001) was slightly adapted for this study by replacing all references to clothing, with interior objects. The final scale included 31 statements that were shuffled in random order. The scale items addressed three types of counter conformity, namely 11 statements each about creative choice counter-conformity (CCC) and unpopular choice counter-conformity (UCCC), and 9 statements about avoidance of similarity (AOS). The five point Likert-type Agreement scale ranged from Strongly Disagree to Strongly Agree. Respondents' primary motivation for interior purchases for the social zones of their homes was investigated through 19 statements contained in a four increment Likert-type Agreement scale. Criteria used for the selection of interior objects for the social zones of their homes as well as the primary inspiration for the objects chosen was investigated through 18 and 5 statements respectively, which were formulated on a similar scale as the former.

\section{Sampling plan and data collection}

This study involved owners or tenants of townhouse units in enclosed housing developments in upmarket suburbs in a fast growing urban area in South Africa where cluster homes have become particularly popular in recent years. The researcher and two trained assistants collected primary data over a period of six months, initially through stratified probability sampling. Due to unforeseen problems, data collection had to be completed through convenient snowball sampling because it became too difficult and time consuming to gain access to the selected complexes. Prior arrangements were made with body corporates who gave permission to proceed with data collection in specific complexes, where after a door-to-door approach was followed to recruit respondents. A drop-off-collect-later method was used to distribute the structured questionnaires. Respondents who agreed to involve other residents in the same or another qualifying townhouse complex assisted with snowball sampling by distributing additional 
questionnaires to acquaintances. Completed questionnaires were returned anonymously in sealed envelopes. Of the 460 questionnaires that were distributed, 236 questionnaires were retrieved, of which only 182 were eligible because some were incomplete, or respondents were either too young ( $<21$ years) or too old ( $>75$ years) in terms of the validity of the data. Incomplete questionnaires may have been the result of discomfort caused by pertinent questions about the interior of respondents' homes which may have created an impression of infringement of privacy, despite assurance of anonymity. Incomplete questionnaires were discarded.

\section{Data analysis}

Data analysis involved descriptive statistics, i.e. calculation of frequencies, means, standard deviations and percentages. Exploratory factor analysis was used to analyse data relating to the 31-item Need for Uniqueness scale and to distinguish the types of counter-conformity. Principal axis factoring served as the extraction method with Oblimin rotation and Kaiser normalisation, which converged in nine iterations. An exploration of criteria that influenced residents' choice of interior objects for their homes was done by means of a 12-item Likert-type agreement scale: items were subjected to a similar exploratory factor analysis procedure.

\section{PROFILE OF THE SAMPLE}

In dual households, the request was for those individuals who were mostly involved or interested in the choice of interior goods for their homes to complete the questionnaires. Eventually, the majority of respondents were females ( $n=120$ / 65.9\%; Males: $n=62 ; 34.1 \%$ ). Respondents' ages ranged between 22 and 75 years, with 48.9\% ( $n=89$ ) younger than 35 years; $37.9 \%(n=69)$ between 35 and 55 years of age; and 13.2\% $(n=24)$ older than 55 years. Questionnaires were completed by 38 heads of single households; 87 who were part of a dual household, and 31 who headed households constituting three or more members. The majority of the sample therefore had to consider other household members about the interior product decisions of their homes. Literature proposes that a typical family that resides in a townhouse mostly constitutes of singles or couples without children (Nussbaumer, 2009, p. 239), which probably explains the composition of this sample in terms of the larger representation of young newly married couples and elderly couples without children. The sample included $21 \%$ single member households $(n=38), 48.1 \%$ dual household members $(n=87)$ and $30.9 \%$ households with three or more members $(n=56)$. The majority of respondents were either married or living with a partner ( $n=111 ; 61.0 \%$ ), while the rest ( $n=70 ; 38.5 \%)$ comprised single, divorced, separated or widowed individuals. The entire sample could be categorized as higher middle- to upper income households in the context of the study (earning approximately 1200 USD\$ per month), which was an intentional decision to ensure that respondents could afford to be selective and even meticulous in terms of their interior product choices. Most of the respondents were well educated, as $77.5 \%(n=141)$ possessed higher than secondary school qualifications, including $48.4 \%$ ( $n=88$ ) with a degree or post graduate qualification. 


\section{RESULTS AND DISCUSSIONS}

\section{Residents' need for uniqueness}

With regard to the Need for Uniqueness analysis, the final correlation matrix of the factor analysis procedure produced three factors that largely coincided with the scale of Tian et al. (2001), except for three items that relocated to alternative factors. Based on these items' respective factor loadings and difficulty to unequivocally exclude them from the factors they relocated to, they were retained as is. Eventually, Factor 1, Creative Choice Counter Conformity (CCCC), contained 12 items including the original 11 items that were associated with this construct; Factor 2, Avoidance of Similarity (AOS), contained 11 items comprising all the original items associated with the construct with inclusion of two items originating from UCCC; while Factor 3, Unpopular Choice Counter Conformity (UCCC), which consisted of 8 items, coincided with the original construct. Acceptable Cronbach Alphas for all three factors $(\geq 0,83)$ and consistent standard deviations across the three factors (0.83 to 0.88$)$ suggest reliable responses. The factors and their respective items explain $52.8 \%$ of the variance in the data, which is acceptable. Findings are presented in Table 1.

Table 1 Interior choices that reflect creative choice counter-conformity behaviour $(\mathrm{n}=175)$

\begin{tabular}{|c|c|c|c|c|}
\hline Statement & F1: CCCC & F2: AOS & F3: UCCC & \\
\hline $\begin{array}{l}\text { I'm on the look-out for new interior products that will add to my personal } \\
\text { uniqueness }\end{array}$ & .835 & .069 & -.161 & 0.90 \\
\hline $\begin{array}{l}\text { When buying interior products an important goal is to find something that } \\
\text { communicates my uniqueness }\end{array}$ & .790 & .082 & .025 & 0.90 \\
\hline I think of how I can use the things I buy to shape a more unusual image & .709 & .082 & .037 & 0.91 \\
\hline The interior products that I like best, are the ones that express my individuality & .702 & -.083 & -.040 & 0.91 \\
\hline $\begin{array}{l}\text { Having an eye for interior products that are interesting and unusual assists me } \\
\text { in establishing a distinctive image }\end{array}$ & .701 & -.042 & .041 & 0.91 \\
\hline $\begin{array}{l}\text { I look for a one of a kind product so that I create a style in my entertainment } \\
\text { areas that is all my own }\end{array}$ & .674 & .096 & -.006 & 0.91 \\
\hline $\begin{array}{l}\text { I actively seek to develop my personal uniqueness by buying special interior } \\
\text { products }\end{array}$ & .672 & .233 & -.054 & 0.91 \\
\hline $\begin{array}{l}\text { I try to find a more interesting version of run of the mill interior products, } \\
\text { because I enjoy being original }\end{array}$ & .632 & .033 & .083 & 0.91 \\
\hline $\begin{array}{l}\text { I combine interior products in such a way that I create a personal image for } \\
\text { myself that can't be duplicated }\end{array}$ & .603 & -.020 & .268 & 0.91 \\
\hline $\begin{array}{l}\text { I have purchased unusual interior products as a way to create a more } \\
\text { distinctive image in my home }\end{array}$ & .493 & .130 & .194 & 0.91 \\
\hline I collect unusual interior products as a way of telling people I am different & .453 & .135 & .231 & 0.91 \\
\hline $\begin{array}{l}\text { Being out of place with my friends doesn't prevent me from having an interior } \\
\text { I want to have }\end{array}$ & .394 & -.094 & .205 & 0.92 \\
\hline $\begin{array}{l}\text { When the interior products I own, become common items, I remove them } \\
\text { from my entertainment areas }\end{array}$ & -.095 & .829 & -.022 & 0.89 \\
\hline $\begin{array}{l}\text { When products that I like become popular among the general population, I } \\
\text { move it out of my entertainment areas }\end{array}$ & -.008 & .787 & -.055 & 089 \\
\hline I try to avoid interior products that are bought by the general public & .254 & .741 & -.098 & 0.87 \\
\hline I remove fashionable interior products from my entertainment areas once they & -.011 & .660 & .106 & 0.89 \\
\hline
\end{tabular}




\begin{tabular}{|c|c|c|c|c|}
\hline become popular by the general public & & & & \\
\hline $\begin{array}{l}\text { Products DON'T seem to hold much value to me, when they are purchased } \\
\text { regularly by everyone }\end{array}$ & .030 & .656 & .004 & 0.90 \\
\hline As a rule I dislike products that are normally purchased by everyone & .154 & .654 & .020 & 0.89 \\
\hline $\begin{array}{l}\text { The more commonplace an interior product is amongst the general population } \\
\text { the less interested I am in buying it }\end{array}$ & .185 & .602 & .070 & 0.89 \\
\hline $\begin{array}{l}\text { I avoid interior products and brands that have already been accepted and } \\
\text { purchased by the average consumers }\end{array}$ & .332 & .576 & -.038 & 0.89 \\
\hline $\begin{array}{l}\text { I enjoy challenging the prevailing taste of people I know by buying things I } \\
\text { know they wouldn't accept }\end{array}$ & -.142 & .471 & .322 & 0.90 \\
\hline When interior products or brands that I like become popular, I lose interest & .034 & .452 & .199 & 0.90 \\
\hline I rarely agree with others on what conventional interior objects to buy & .209 & .275 & .178 & 0.90 \\
\hline $\begin{array}{l}\text { If someone hinted that my interior is deemed as inappropriate, I will continue } \\
\text { decorating in the same fashion }\end{array}$ & -.019 & .002 & .668 & 0.80 \\
\hline $\begin{array}{l}\text { When my interior is deemed as different I am aware that others think I am } \\
\text { peculiar, but I DO NOT care }\end{array}$ & .190 & -.165 & .649 & 0.80 \\
\hline $\begin{array}{l}\text { When it comes to the interior products I buy and the situations in which I use } \\
\text { them, customs and rules are made to be broken }\end{array}$ & .174 & .121 & .505 & 0.79 \\
\hline $\begin{array}{l}\text { I have violated the understood rules of my social group, regarding what to buy } \\
\text { or own }\end{array}$ & .200 & .084 & .492 & 0.80 \\
\hline $\begin{array}{l}\text { I have unconventional interior products in my home, even when it's likely to } \\
\text { offend others }\end{array}$ & .054 & .204 & .483 & 0.80 \\
\hline $\begin{array}{l}\text { I have gone against the understood rules of my social group regarding when } \\
\text { and how certain interior products are properly used }\end{array}$ & -.073 & .240 & .473 & 0.81 \\
\hline $\begin{array}{l}\text { When it comes to the interior products I buy, and the situations in which I use } \\
\text { them, I have broken customs and rules }\end{array}$ & .222 & .066 & .408 & 0.81 \\
\hline $\begin{array}{l}\text { I decorate my entertainment areas in a way that others are likely to } \\
\text { DISAPPROVE of }\end{array}$ & -.046 & .283 & .336 & 0.82 \\
\hline Mean* & 3.29 & 2.30 & 2.60 & \\
\hline Std dev & 0.88 & 0.83 & 0.83 & \\
\hline Cronbach Alpha & 0.91 & 0.90 & 0.83 & \\
\hline \% Variance Explained & 37.66 & 9.39 & 5.75 & \\
\hline
\end{tabular}

Based on the findings presented in Table 1, H1 is accepted with respect to Factor 1 , creative choice counterconformity $\left(M_{\mathrm{cccc}}=3.29, \mathrm{M}_{\mathrm{Max}}=5.0\right)$, indicating a predominant selection and consumption of interior objects that are novel yet acceptable and sanctioned by one's social group (Ruvio et al., 2008). This type of counter conformity implies conscious effort to seek new interior products that will enhance residents' personal uniqueness; consideration of ways to use interior objects to create a more unusual image; effort to create a personal, distinctive style through the acquisition of special and original products that others will find difficult to duplicate; as well as the collection of unusual interior products that would indicate to others that you are different (Tian et al., 2001). In terms of a need to distinguish your home from others in the same housing complex, this is however the least adventurous endeavour, which poses the least social risk. Evidence to support avoidance of similarity (Factor 2), the more severe form of 
counter conformity, is lacking $\left(\mathrm{M}_{\mathrm{AOS}}=2.30\right)$, which rejects this form of counter conformity as a typical reflection of townhouse residents' interior choices. Findings do however support the likelihood of unpopular choice counter conformity $\left(F 3: \mathrm{M}_{u c c c}=2.60\right)$, i.e. making unconventional product choices that deviate from one's reference group, which may even violate the norm. This type of behaviour is typical of innovators that may eventually win the admiration of their social peers (Ruvio et al., 2008). Findings hence suggest a disposition of residents of town houses towards unpopular choice counter-conformity, which results in partial acceptance of $\mathrm{H} 1$ for this particular dimension of counter conformity.

\section{Differences within demographic groups}

A GLM investigation followed to determine possible significant differences in residents' counter conformity behaviour within the different demographic groups as presented in Table 2. The dataset included 155 useful observations after exclusion of incomplete data sets.

Table 2 Categories of investigation

\begin{tabular}{|r|l|}
\hline Gender & Male; Females \\
\hline Age Categories (years) & $<25 ; 25-34 ; 35-54 ;>=55$ \\
\hline Household Income Categories & $<=15000 ;>15000-19000 ;>19000-30000 ;>30000-40000 ;>40000$ \\
\hline Tenure Status & Own; Rent \\
\hline
\end{tabular}

In terms of the most dominant form of counter-conformity, i.e. home owners' propensity to demonstrate creative counter conformity behaviour (CCCC) through their interior product decisions, statistically significant differences could only be confirmed for gender in the model which simultaneously investigated differences within the selected demographic groups. Although a fairly conservative way to express one's uniqueness, there seems to be a significantly higher tendency for females $(n=102)$ compared to males $(n=54)\left(M_{F}=3.40 ; M_{M}=2.97 ; p=0.0028\right)$, to demonstrate their uniqueness through CCCC. This implies selecting interior products that differ from the run-of-the-mill objects, and which are novel compared to those chosen by their social group. H2, i.e. proposing that females will demonstrate significantly stronger counter conformity behaviour when choosing interior products for their homes than males, is therefore not rejected for UCCC, but rejected for AOS as well as UCCC. In terms of the other two, more challenging modes of counter conformity, significant differences could therefore not be confirmed within any of the demographic categories (AOS: $p=0.81 / R^{2}=0.034$; UCCC: $p=0.6004 / R^{2}=0.048$ ). $H 3, \mathrm{H} 4$ as well as $\mathrm{H} 5$ are therefore rejected based on evidence that neither age, household income or tenure status significantly influence homeowners' demeanour to demonstrate their uniqueness. Although means for females were constantly higher compared to the 
findings for males (AOS: $M_{F}=2.37 ; M_{M}=2.14 ; U C C C: M_{F}=2.62 ; M_{M}=2.43$ ), differences were not statistically significant $(p>0.05)$.

\section{Preferred product characteristics}

Responses to the list of 12 product characteristics were subjected to exploratory factor analysis, namely Principal Components with Promax rotation, considering Eigen values $>1.5$. Four factors containing three items each, emerged as listed in Table 3. The factors were labelled: Factor 1: Original and valuable; Factor 2: Exclusive; Factor 3: Limited/Scarce; Factor 4: Impressive. Residents' apparent preference for exclusive interior objects ( $M=3.35 ;$ Max=4) alludes a fairly strong need to acquire objects that are not run-of-the-mill, i.e. evidence of CCCC. Preference for originality ( $M=2.93$ ) confirms residents' need to differentiate their homes, while to a lesser extent, objects had to be scarce $(M=2.61)$. Being impressive or extraordinary $(M=2.33)$ was not necessarily a strong requirement.

Table 3 Preferred product characteristics

\begin{tabular}{|l|r|r|r|r|}
\hline Statements & \multicolumn{1}{|l|}{$\begin{array}{l}\text { Factor 1 } \\
\text { Original }\end{array}$} & $\begin{array}{l}\text { Factor 2 } \\
\text { Exclusive }\end{array}$ & $\begin{array}{l}\text { Factor 3 } \\
\text { Limited }\end{array}$ & \multicolumn{1}{l|}{$\begin{array}{l}\text { Factor 4 } \\
\text { Impressive }\end{array}$} \\
\hline $\begin{array}{l}\text { I would rather save for original paintings, than to purchase } \\
\text { and hang prints in the entertainment areas of my home }\end{array}$ & 0.86784 & 0.04285 & -0.00988 & -0.09241 \\
\hline $\begin{array}{l}\text { I regard objects in the entertainment areas of my home as } \\
\text { investments and therefore prefer to source original objects }\end{array}$ & 0.86527 & 0.06642 & 0.02891 & 0.01044 \\
\hline $\begin{array}{l}\text { I prefer hand crafted/designer accessories and furniture to } \\
\text { mass produced accessories and furniture }\end{array}$ & 0.6406 & -0.02207 & 0.22311 & 0.20137 \\
\hline $\begin{array}{l}\text { I prefer to shop at a large variety of stores for my interior } \\
\text { goods, rather than to purchase most of what I need at a } \\
\text { single store }\end{array}$ & 0.1063 & 0.75183 & -0.10304 & -0.0437 \\
\hline I purchase beautiful objects, even if it is less expensive & -0.19773 & 0.71067 & 0.33113 & 0.04347 \\
\hline $\begin{array}{l}\text { I save up until I can purchase what I desire i.e. I don't settle } \\
\text { for second best }\end{array}$ & 0.39554 & 0.69103 & -0.12566 & -0.03875 \\
\hline I use second hand furniture that are functional and useful & -0.00309 & -0.03166 & 0.89269 & -0.32129 \\
\hline I prefer to purchase antique/scares objects & 0.20744 & 0.0458 & 0.64117 & 0.22274 \\
\hline $\begin{array}{l}\text { I select and purchase individual items rather than whole sets } \\
\text { e.g. an entire lounge suite }\end{array}$ & 0.08143 & -0.03856 & 0.50694 & 0.4356 \\
\hline $\begin{array}{l}\text { I purchase interior objects that I need for my home at } \\
\text { specialized outlets rather than major prominent retail stores }\end{array}$ & 0.15947 & -0.17969 & -0.08192 & 0.75262 \\
\hline $\begin{array}{l}\text { I prefer objects that are impressive even if it is less } \\
\text { functional }\end{array}$ & -0.00828 & 0.10342 & -0.04639 & 0.67675 \\
\hline I buy products that look expensive, even if they are not & -0.30706 & 0.3533 & -0.06333 & 0.49886 \\
\hline Mean & 2.93 & 3.35 & 2.62 & 2.32 \\
\hline \% Std dev & 0.98 & 0.94 & 0.82 & 0.65 \\
\hline
\end{tabular}


A following question confirmed the findings. It involved an investigation of the importance of selected aestheticsrelated characteristics when considering interior objects for their homes as deduced from literature, excluding functional performance related features. Table 4 demonstrates respondents' preference for original objects $(>70 \%)$, which indicates a strong need to be unique rather than to display branded and expensive objects that are associated with status and which may evoke admiration without necessarily discriminating your home from others.

Table 4 The importance of selected purchase criteria $(n=182)$

\begin{tabular}{|l|r|r|r|r|}
\hline Purchase criteria & \multicolumn{2}{|l|}{ Agree } & \multicolumn{1}{l|}{ Mean } & \multicolumn{1}{l|}{ Std dev. } \\
\hline & \multicolumn{1}{|c|}{$\mathbf{n}$} & \multicolumn{1}{l|}{$\%$} & & \\
\hline Original & 129 & 72.5 & 2.93 & 0.98 \\
\hline Exclusive & 80 & 46.5 & 2.31 & 1.05 \\
\hline Branded & 44 & 25.4 & 1.96 & 0.90 \\
\hline Expensive & 31 & 18.1 & 1.74 & 0.84 \\
\hline
\end{tabular}

Possible differences in residents' regard for product features were investigated within gender (Male: $n=61, M=1.84$; Female: $n=110, M=1.69$ ); age ( $<35$ yrs: $n=89, M=1.69 ; \geq 35-<50: n=89, M=1.67 ; \geq 50: n=34, M=2.0$ ); and level of education groups ( $\leq$ Grade 12: $n=35, M=1.83$; Post-secondary certificate/ diploma/ degree: $n=94, M=1.74$; Post graduate degree/diploma: $n=42, M=1.67)$; residents who owned $(n=102: M=1.79)$ or rented $(n=69, M=1.69)$ their homes; as well as differences in duration of tenure $(<5$ yrs: $n=96, M=1.80 ; \geq 5$ yrs: $n=49, M=1.83$ ). Significant differences within the various demographic groups could only be confirmed for gender, specifically in terms of residents' attention to product features. A t-test revealed that males $(M=2.16)$ are significantly more attentive to branded products than their female counterparts ( $M=1.85 ; p=0.0267)$, although the means suggest that brands per se, were not necessarily highly important $\left(\mathrm{M}_{\mathrm{Max}}=4\right)$.

\section{Sources of interior inspiration}

Since the socialization process has a major influence on a person's expression of the extended self (Wilska, 2002; Sandstrom et al., 2006, p. 58), the relevance of different sources of inspiration on residents' interior design and décor choices was also investigated. Findings suggest that residents largely depend on interior shows and exhibitions ( $n=135,75.4 \%$ ), where more exclusive products and new trends are introduced, which supports evidence of CCCC. Smaller reliance on immediate family $(n=106,59.2 \%)$, friends $(n=93,52.8 \%)$ and peers $(n=91,51.7 \%)$ was therefore expected as their views would not necessarily enhance counter conformity in choice. Consultation of interior designers was probably only used by those who could afford to $(n=29,16.4 \%)$. Anova indicated that the influence of immediate family was significantly stronger on younger residents $(<35$ years: $M=2.78)$ than those of 50 years and older ( $M=2.22 ; p=0.0055)$. Similarly, younger residents' reliance on friends as a source of inspiration ( $<35$ years: $M=2.43$ ) was significantly stronger compared to the over 50 age group $(M=2.03 ; p=0.0256)$. The same applied to 
residents $>35$ up to 50 years of age $(M=2.54)$ compared to the eldest group $(p=0.0097)$. Therefore residents seem to become less reliant on friends' advice by the time they reach middle age, probably due to increased experience and lower financial pressure at a later stage in life. Significant differences were also exposed with regard to males' and females' use of media, including lifestyle magazines, television programmes and interior shows as source of inspiration $\left(M_{F}: 3.19 ; M_{M}: 2.52 ; p<0.001\right)$. Females seem significantly more inclined to use popular media as sources of inspiration.

\section{CONCLUSIONS AND RECOMMENDATIONS}

Due to the visibility of interior products in the social zone of one's home, the actual interior product choices may create internal conflict. On the one hand, people who choose to conform will do so to abide with social norms, to avoid criticism and to gain the approval of others, in order to gain rewards for such behaviour, e.g. social acceptance, which probably explains the prevalence of creative choice counter-conformity behaviour. On the other hand, a person who chooses to counter-conform, may pertinently endeavour to promote or enhance his/ her self- and social image through a demonstration of their uniqueness (Simonson and Nowlis, 2000). Townhouse residents who took part in this investigation resided in homes that were almost identical to neighbouring homes in their complex. In the context of this study, creative choice counter-conformity, which is the less risky route to express one's need for uniqueness, was found to be most prevalent in residents' interior product decisions. Townhouse residents thus seem to choose interior objects that are novel yet still socially accepted by their reference- and peer groups, and which will not evoke strong criticism. Although less prevalent than the former, unpopular choice counter-conformity (UCCC), which is a more extreme form of counter conformity behaviour, seems viable. Despite evidence of CCCC, and indications of UCCC the study could however not confirm a particularly strong need for uniqueness as expected, i.e. AOS. Possibly people with a strong need for uniqueness would most likely not consider developments where housing units are visually identical or very similar. Residents' preference for exclusive, original interior objects, rather than branded or impressive objects confirm creative choice counter conformity rather than status consciousness. In addition, trade shows and media, were used as primary source of inspiration especially by residents in the middle to older age groups who can probably more easily afford novel, trendy products. These shows generally introduce novel designs and trends while the advice of friends, family and peers, might be more conventional.

The findings of this study would be useful for developers, interior designers and -decorators as well as the interior retail environment. Developers could for example allow for greater differentiation in terms of the fixtures in the interior of townhouses so that homes that are visually similar on the exterior, can spark some unexpected pleasure and excitement when entered into. When involving prospective buyers or interior consultants from an earlier stage, developers could personify the interiors of individual units through customisation of the interior fixtures to increase 
residents' satisfaction, interest in this type of tenure and enhance the possibility of place atatchement. Based on insignificant differences within demographic categories, retail should acknowledge the role of non-traditional customers, for example males, and older consumer in their marketing and sales approaches rather than to focus on females and younger people in promotional material.

The Need for Uniqueness Scale (Tian et al., 2001) is based on visual rather than verbal communication of uniqueness. Therefore it is considered a product orientated scale that corresponds with conceptual marketing models of consumers' responses to the exterior design of products, their fashion cycles and variety seeking behaviour, which are all relevant to interior merchandise. The type of counter-conformity employed evokes different reactions in a person's social group and society as a whole. The findings of this study contribute to the existing body of literature, which is limited in terms of consumers' housing and interior decisions, in particular on how the housing type one resides in, influences residents' interior choices. In this study, the Need for Uniqueness Scale that was originally developed in a clothing context (Tian et al., 2001) has been adapted and implemented successfully (Cronbach Alpha $\geq 0.84$ ) relating to interior merchandise, which is useful for future research.

Several opportunities for further research exist. A larger, more representative sample recruited from a wider geographic area would allow generalizable findings, which is recommended because of the growth in townhouseliving in recent years. A qualitative approach would provide opportunity to gain an in-depth understanding of consumers' use of interior objects in their townhouses and to determine whether people with a strong need for uniqueness avoid this type of tenure intentionally because it may be too inhibiting.

\section{REFERENCES}

Adams, J.S. (1984) Presidential address: the meaning of housing in America. Annals of the Association of American Geographers, 74(4), 515-526.

Adriaenssens, S. \& Hendrickx, J. (2009) Modes of production in home maintenance: accounting for the choice between formality, off the books and self-provisioning. International Journal of Consumer Studies, 33(5), 596-603.

Allen, P.S., Jones, L. \& Stimpson, M.F. (2004) Beginnings of Interior Environments, 9th edn. Pearson, Prentice Hall, NJ.

Belk, R.W. (2010) Sharing. Journal of Consumer Research, 36(1), 715-734.

Belk, R.W. (1988) Extended self and extending paradigmatic perspective. Journal of Consumer Research, 16(1), 129132.

Binggelli, C. (2007) Interior Design. A Survey. John Wiley, New Jersey. 
Blandy, S. (2006) Gated communities in England: historical and current developments. Geo Journal, 66(1), 15-26.

Bowers, B.S. \& Manzi, T. (2006) Private security and public space: new approaches to the theory and practice of gated communities. European Journal of Spatial Development, 22(1), 1-17.

Casimir, G.J. \& Tobi, H. (2011) Defining and using the concept of household: a systematic review. International Journal of Consumer Studies, 35(5), 498-506.

Charon, J.M. (1979) Symbolic Interactionism: an Introduction, an Interpretation, an Integration. Prentice Hall, New Jersey.

Clapham, D. (2005) The Meaning of Housing: A Pathways Approach. Policy Press, Bristol.

Coy, M. \& Pöhler, M. (2001) Gated communities in Latin American megacities: case studies in Brazil and Argentina. Environment and Planning and Design, 29(1), 355-370.

Creusen, M.E.H. \& Schoormans, J.P.L. (2005) The different roles of product appearance in consumer choice. The Journal of Product Innovation Management, 22(1), 63-81.

Cuba, L. \& Hummon, D.M. (1993) Constructing a sense of home: place affiliation and migration across the life cycle. Sociological Forum, 8(4), 547-572.

Delport, H. (2002) An Introduction to the Fundamental Principles of Estate Agency, 3rd edn. Juta, Cape Town.

Dunn, J.R. (2002) Housing and inequalities in health: a study of socioeconomic dimensions of housing and self reported health from a survey of Vancouver residents. Journal of Epidemiol Community Health, 56(9), 671-681

Fernandez, K.V. (2008) Protecting the portals of home. Advances in Consumer Research, 35(1), 774-775.

Fischer, M. \& Stamos, M.Z. (2013) Optimal life cycle portfolio choice with housing market cycles. The Review of Financial Studies, 26(9), 2310-2352.

Flambard, V. (2013) Housing allowances and forced moves. International Journal of Housing Policy, 13(2), $159-182$.

Guest editorial. (2009). A consumer perspective on housing. International Journal of Consumer Studies, 33(5), 521-524.

Gunter, B. (2000) Psychology of the home. Wurr, London.

Han, L. (2013) Understanding the puzzling risk-return relationship for housing. The Review of Financial Studies, 26(4), $877-928$. 
Hook, D. \& Vrdjolak, M. (2002) Gated communities, heteropia and a "rights" of privilege: a "heterotopology" of the South African security park. Geoforum, 33(1), 195-219.

JürgenS, U. \& Gnad, M. (2002) Gated communities in South Africa- experiences from Johannesburg. Environment and Planning B: Planning and Design, 29(1), 337-353.

Kaiser, S.B. (1998) The Social Psychology of Clothing: Symbolic Appearances in Context. Fairchild, New York.

Kemeny, J. (1992) Housing and Social Theory. Routledge, Basingstoke.

Kempen, E. \& Ozaki, R. (2006) Psychological meanings of living rooms in the management of impression and identity: a literature review. Social Psychological Review, 8(2), 89-102.

Kilmer, R. \& Kilmer, W.O. (1992) Designing Interiors. Thomson Learning, United States of America.

Knez, I. (2005) Attachment and identity as related to a place and its perceived climate. Journal of Environmental Psychology, 25(1), 207-218.

Kopec, D.A. (2006) Environmental Psychology for Design. Fairchild, New York.

Lamb, C.W., Hair, J.F., McDaniel, C., Boshoff, C. \& Terblanche, N.S. (2004) Marketing, 2nd edn. Oxford University Press, Cape Town.

Lee, C.L. \& Reed, R.G. (2014) The relationship between housing market intervention for first-time buyers and house price volatility. Housing Studies, 29(8), 1073-1095.

Lollar, K. (2010) The liminal experience: loss of extended self after the fire. Qualitative Inquiry, 16(4), $262-270$.

Mannarini, T., Targalia, S., Fedi, A. \& Greganti, K. (2006) Image of neighbourhood, self-image and sense of community. Journal of Environmental Psychology, 26(3), 202-214.

Manzo, L.C. (2003) Beyond house and haven: toward a revisioning of emotional relationships with places. Journal of Environmental Psychology, 23(1), 47-61.

Maury, T.P. \& Tripier, F. (2014) Search strategies on the housing market and their implications on price dispersion. Journal of Housing Economics, 26, 55-80.

Miller, D. (ed.) (2001) Home Possessions: Material Cultures behind Closed Doors. Berg, Oxford and New York. Moore, J. (2000) Placing home in context. Journal of Environmental Psychology, 20(1), 207-217. 
Morgan, F. (2009) Advantages of condo living- the why's and how's of lifestyle improvement. [WWW document]. URL http://fmorgan.articlealley.com/advantages-to-condo-living-the-whys-and-hows-of-lifestyle-improvement1005430.html (accessed on 25 February 2014).

Nielson, K.J. \& Taylor, D.A. (2007) Interiors: An Introduction, 4th edn. Fairchild, New York.

Nunn, T.L., Sweaney, A.L., Cude, B.J. \& Hathcote, J.M. (2009) Consumer receptiveness to universal design features. International Journal of Consumer Studies, 33(1), 11-19.

Nussbaumer, L.L. (2009) Evidence Based Design for Interior Designers. Fairchild, New York.

Pitrowski, C. (2004) Becoming an Interior Designer. John Wiley, New Jersey.

Quitzau, M. \& Røpke, I. (2008) The construction of normal expectations: consumption drivers for the Danish bathroom boom. Journal of Industrial Ecology, 12(2), 186-206.

Rahman, A. \& Harding, A. (2014). Spatial analysis of housing stress estimation in Australia with statistical validation. Australasian Journal of Regional Studies, 20(3), 452-486.

Rengel, R.J. (2007) Shaping Interior Space, 2nd edn. Fairchild, New York.

Roth, K. (2006) Everything you Need to Know before Buying a Co-Op, Condo, or Townhouse. American Management Association, New York.

Ruvio, A., Shoham, A. \& Brenčič, M.M. (2008) Consumer's need for uniqueness: short-form scale development and cross-cultural validation. International Marketing Review, 25(1), 33-53.

Sanchez, T.W., Lang, E.L. \& Dhavale, D.M. (2005) Security versus status: a first look at the census's gated community data. Journal of Planning Education and Research, 24(1), 281-291.

Sandstrom, K.L., Martin, D.D. \& Fine, G.A. (2006) Symbols, Selves and Social Reality: a Symbolic Interactionist Approach to Social Psychology and Sociology, 2nd edn. Roxbury, Los Angeles.

Schiffman, L.G. \& Kanuk, L.L. (2010) Consumer Behaviour. Global Edition, 10th edn. Prentice Hall, New Jersey.

Schultz, S.E., Kleine, R.E. \& Kernan, J.B. (1989) "These are a few of my favourite things": Toward an explication of attachment as a consumer behaviour construct. Advances in Consumer Research, 16(1), 359-366.

Simonson, I. \& Nowlis, S.M. (2000) The role of explanations and need for uniqueness in consumer decision making: unconventional choices based on reasons. Journal of Consumer Research, 27(1), 49-68. 
Solomon, M.R. (2007) Consumer Behaviour: Buying, Having and Being, 7th edn. Pearson Education, New Jersey.

Stets, J.E. \& Burke, P.J. (2000) Identity theory and social identity theory. Social Psychology Quarterly, 63(3), $224-237$.

Tepper, K. \& Hoyle, R.H. (1996) Latent variable models of need for uniqueness. Multivariate Behavioural Research, 31(4), 467-494.

The Past Whispers. (Doors of Dublin). [WWW document]. URL http://www.thepastwhispers.com/Doors_of_Dublin. html (accessed on 5 February 2014).

Tian, K. \& Belk, R.W. (2005) Extended self and possessions in the workplace. Journal of Consumer Research, 32(2), 297310.

Tian, K.T. \& McKenzie, K. (2001) The long-term predictive validity of the consumers' need for uniqueness scale. Journal of Consumer Psychology, 10(3), 171-193.

Tian, K.T., Bearden, W.O. \& Hunter, G.L. (2001) Consumers' need for uniqueness: scale development and validation. Journal of Consumer Research, 28(1), 50-66.

Van Gorp, J. (2005) Youth Identity and consumption: a research model. Draft paper. 7th Conference of the European Sociological Association, 9 September-12 September 2005.

Warde, A. (2005) Consumption and theories of practice. Journal of Consumer Culture, 5(2), 131-153.

Wilska, T.A. (2002) Me -- A Consumer? Consumption, Identities and Lifestyles in Today's Finland. Acta Sociologica, 45(3), 195-210.

Workman, J.E. \& Kidd, L.K. (2000) Use of the Need for Uniqueness Scale to characterize fashion consumer groups. Clothing and Textile Research Journal, 18(4), 227-236.

Zhang, Y., Zhang, H. \& Seiler, M.J. (2014). The effects of demand specification and search patience on the buyer search process in China's resale housing market: an experimental study. International Real Estate Review, 17(3), 275299. 